Journal of

Cardiology and Vascular Medicine

\title{
Common Indications and Retriever of IVC Filter Placement in Nigeria: Three
} Case Series

\section{Edafe $\mathrm{EA}^{1, *}$, OKORO TEO ${ }^{1}$, Stanley $\mathrm{CN}^{2}$}

${ }^{1}$ Bayelsa Specialist Hospital, Yenagoa, Nigeria

${ }^{2}$ Department of Pharmaceutical Microbiology, University of Port Harcourt

${ }^{\star}$ Corresponding author: Emmanuel Auchi Edafe, bayelsa specialist hospital Nigeria; Tel: 08038735252, E-mail: dremmanueledafe@gmail.com

Received Date: December 11, 2019 Accepted Date: January 09, 2020 Published Date: January 11, 2020

Citation: Edafe EA (2020) Common Indications and Retriever of IVC Filter Placement in Nigeria: Three Case Series. J Cardio Vasc Med 6: 1-9.

\begin{abstract}
There are many reasons for Inferior Vena Cava (IVC) filter placement. Even with the expanding lists of indications, most guidelines recommend that contraindications to systemic thrombolysis or its failure may necessitate IVC filter placement. The increased use may be due to the insertion of retrievable filters. We report three cases with indications for IVC filter placement.

Keywords: Indications; IVC filter placement; infra-renalInferior Vena Cava (IVC)
\end{abstract}




\section{Introduction}

IVC is a vein that carries deoxygenated blood from the lower limbs, pelvic and abdominal organs to the heart. According to the recommendations of American Society of Echocardiography (ASE) guidelines and European Association of Echocardiography (EAE), the IVC was described as small when the diameter was $<1.2 \mathrm{~cm}$, normal when the diameter measured between 1.2 and $1.7 \mathrm{~cm}$ and dilated when it measured $>1.7-2.5$ $\mathrm{cm}$, markedly dilated when it $>2.6 \mathrm{~cm}$. $[1,2]$ The commonest source of pulmonary embolism is deep vein thrombosis (DVT) from the lower limb and the pelvic region [3]. An IVC filter is one method that helps prevent pulmonary embolism. In this 3 case series, we report the common indications for inferior vena cava (IVC) filter placement in Nigeria.

\section{Case 1}

Mr. PSCW was 86 year old man living with hypertension for 39 years and 5 years history of metastatic cancer of the prostate. He presented to the cardiac catheterization laboratory (Cath lab) of Bayelsa Specialist Hospital with 3 weeks history of left leg swelling and pain. His D-dimer was 2400ng/ml. The Duplex ultrasound showed extensive thrombosis of the left superficial and common femoral veins. He was placed on warfarin $5 \mathrm{mg}$ daily. He was on this dose with the last INR of 2.8 within 2 weeks of deep venous thrombosis (DVT). He developed massive upper gastro-intestinal (GI) bleeding that necessitates 12 units of blood transfused in 24 hours on the third week of medication. This was followed by emergency upper GI therapeutic endoscopy with an injection of sclerosant on the stomach ulcer. The patient was then transferred to our cardiac catheterization laboratory for inferior vena-cava filter implantation. Warfarin was stopped. Pre-procedure inform consent was taken. Packed cell volume after the 12 units of blood was transfused was $23 \%$ and $\mathrm{Hb} 7.0 \mathrm{~g} / \mathrm{dl}$, Na was $141 \mathrm{mmol} / \mathrm{dl}$, K was $3.8 \mathrm{mmol} / \mathrm{dl}$, urea was $3.9 \mathrm{mmol} / \mathrm{dl}$ and creatinine was $72 \mu \mathrm{mmol} / \mathrm{dl}$. He was counseled on the complications of IVC filter including fracture and embolization, thrombogesis, migration, and penetration.

Procedure: The right groin was prepared with a butadiene solution in sterile technique. This was followed with $10 \mathrm{mls}$ of $2 \%$ lignocaine after draping the patient. The common femoral vein was accessed via blind puncture and the guide wire passed to the right common iliac vein. The intra-renal segment of the IVC was located with an injection of 20 MLS of omnipaque. This was to visualize the renal vein and the IVC diameter $(24 \mathrm{~mm})$. The IVC filter (7F sheath, ALN IVC filter) was placed at $\mathrm{L}_{3,}$ (an intra-renal segment of the inferior vena cava). (see figure 1). The procedure was uneventful.

Post-procedure: He was transfused with 3 more units of packed cells. IV antibiotics and omeprazole continued in the hospital for 1 week. He was discharged home after a week of hospital stay (28 $8^{\text {th }}$ March 2019). He is clinically stable. He is on compression stocking and physiotherapy. He was also counseled on the need of regular clinic check, the need to remove the filter at our center when the DVT resolved.

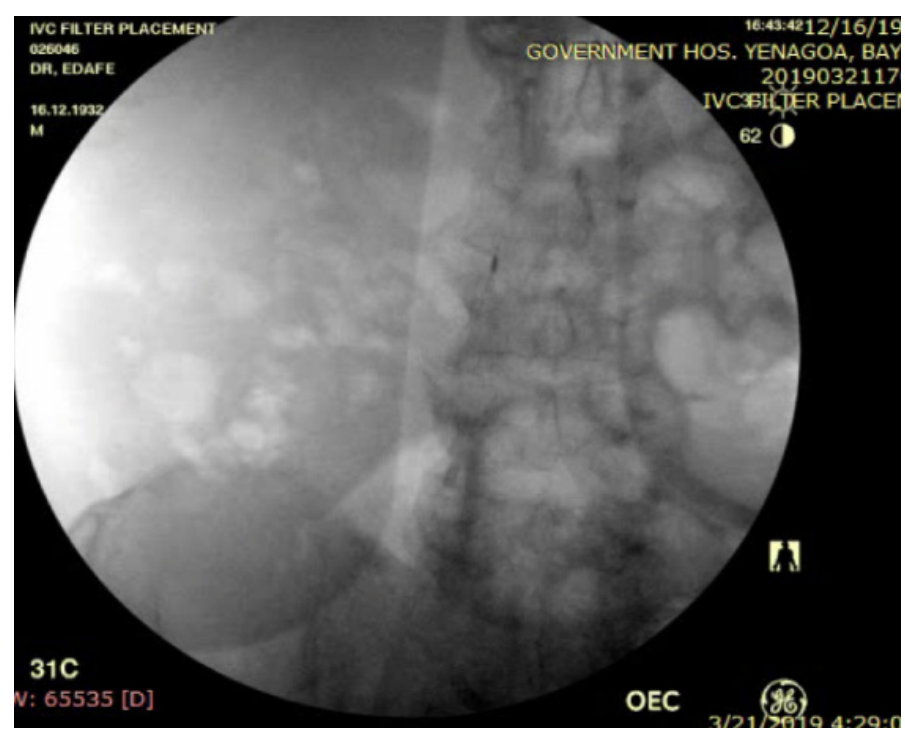

Figure 1: infra-renal IVC segment at $\mathrm{L}_{3}$

Follow up: the follow up was uneventful until the $5^{\text {th }}$ month. He developed meddle ear infection with brain abscess. He was re-admitted to the Intensive care unit for the Otolaryngology and Neurology to manage on the $18^{\text {th }}$ August 2019. The middle ear and brain persisted with sepsis. He died on the $14^{\text {th }}$ day of hospital admission from cardiopulmonary collapse on background hypertension, metastatic cancer of the prostate.

\section{Case 2}

Mr. PN was 73-year-old man living with type 2 Diabetes Mellitus (T2DM) and hypertension for 16 years. History of Pulmonary Embolism one year ago and on Dabigatran $150 \mathrm{mg}$ twice daily. Sillon this medication, he developed left leg swelling and pain of 2 weeks. D-dimer was as 4,120ng/ml. Duplex ultrasound showed deep venous thrombosis (DVT) of the left popliteal, superficial femoral vein (non-compressible and demonstrated no color flow on imaging). He was transferred to the cardiac catheterization center of the Bayelsa Special Hospital for IVC filter placement. The procedure and complications were explained to the patient and relative (son). Informed consent was taken for the procedure. 
Procedure: Sterile procedure was followed. The right groin was prepared with butadiene. The right common femoral vein with a needle and accessed with a blind puncture and the guide wire was passed to the IVC. A venogram was carried out with IVC diameter measurement $(23.6 \mathrm{~mm})$, and position of the renal veins. Deployment of the IVC filter (7F sheath, ALN IVC filter) at the infra-renal renal segment. (see figure 2) The procedure was uneventful.

Post-procedure: He was clinically stable. He continued his anti-diabetic and antihypertensive medications. He was discharged home on the $4^{\text {th }}$ day of hospital admission on the $27^{\text {th }}$ of April 2019.

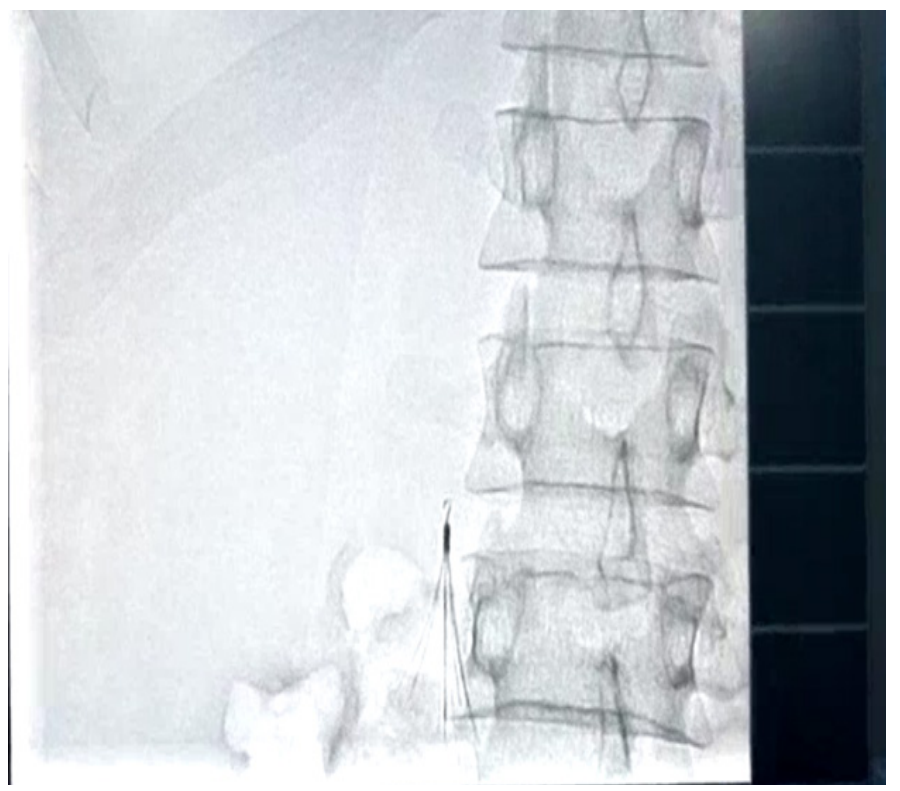

Figure 2: infra-renal ALN IVC filter.

Follow up: He is visiting the outpatient clinic for follow up. The repeat Duplex ultrasound still showed a clot in his lower limb veins. The removal of the filter was discussed with him when the DVT resolved.

\section{Case 3}

An 89-year-old female living with diabetes mellitus for 30 years, hypertension for 10 years and Dyslipidemia for 8 years. The patient had left hemispheric cerebrovascular disease (hemorrhagic) for 2 weeks (figure 3). While in the hospital within these 2 weeks, she developed right leg swelling and pain. Due to a contraindication to anticoagulation, a retrievable inferior vena cava filter was planned for her. Duplex ultrasound showed deep venous thrombosis (DVT) of the right superficial and common femoral vein (non-compressible and demonstrated no color flow on imaging). The D-dimer was $6300 \mathrm{ng} / \mathrm{ml}$, Informed consent was taken after explaining the procedure to the patient and relative.
Procedure: Sterile procedure was followed. The left groin was prepared with butadiene. The left common femoral vein was accessed with a blind puncture needle and the guide wire was passed to the IVC. A venogram was carried out with IVC diameter measurement $(24.2 \mathrm{~mm})$, and position of the renal veins. Deployment of the IVC filter (7F sheath, DENALI IVC filter) at the infra-renal renal segment. (figure 4 and figure 5) The procedure was uneventful.

Post-procedure: the patient continues physiotherapy, compression stocking, anti-diabetic and antihypertensive medications. She was discharged home on the $13^{\text {th }}$ day after the IVC filter implantation. She continued physiotherapy and outpatient clinic care.
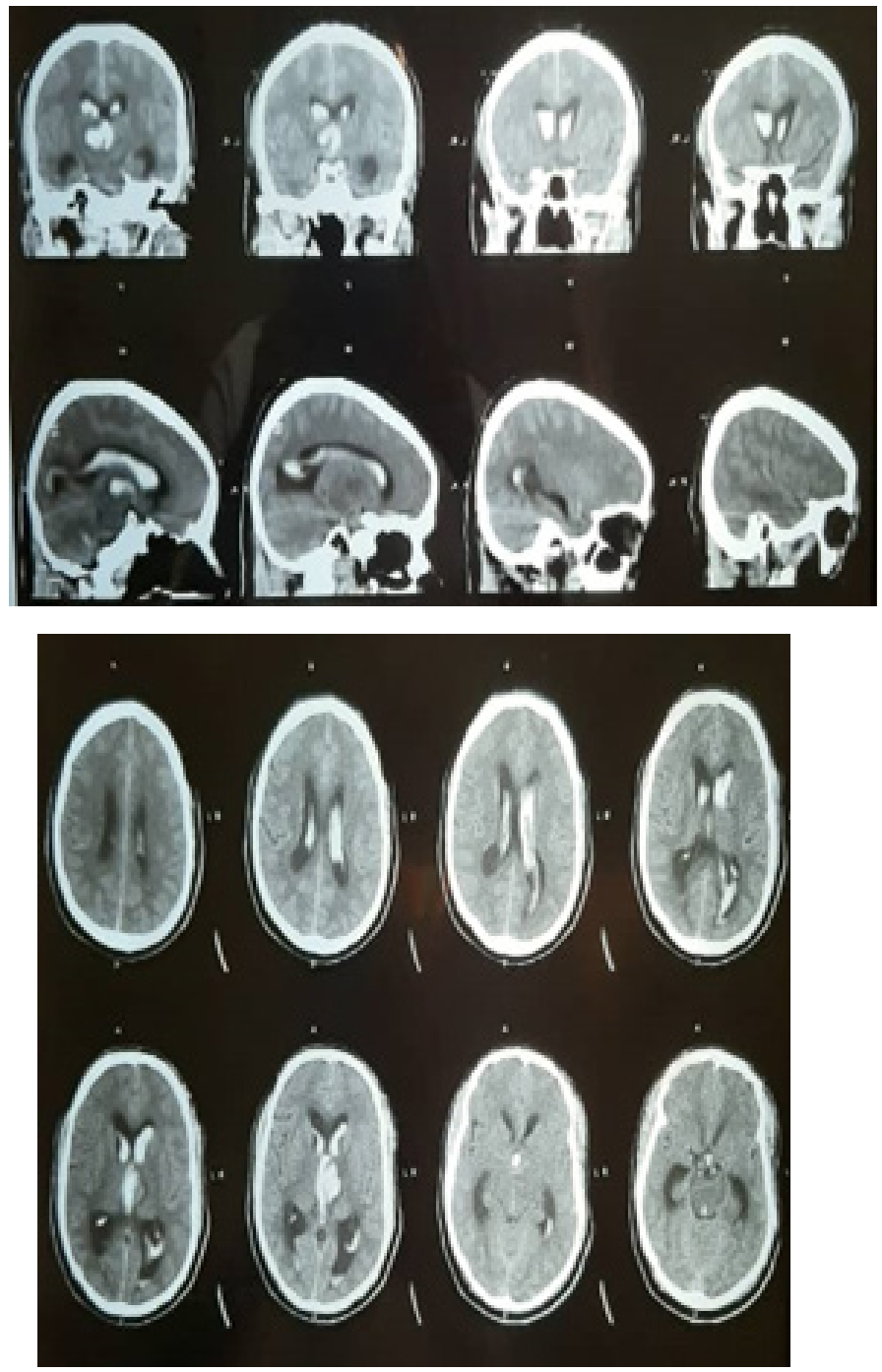

Figure 3: brain Computer Tomography showing intra-ventricular bleed 


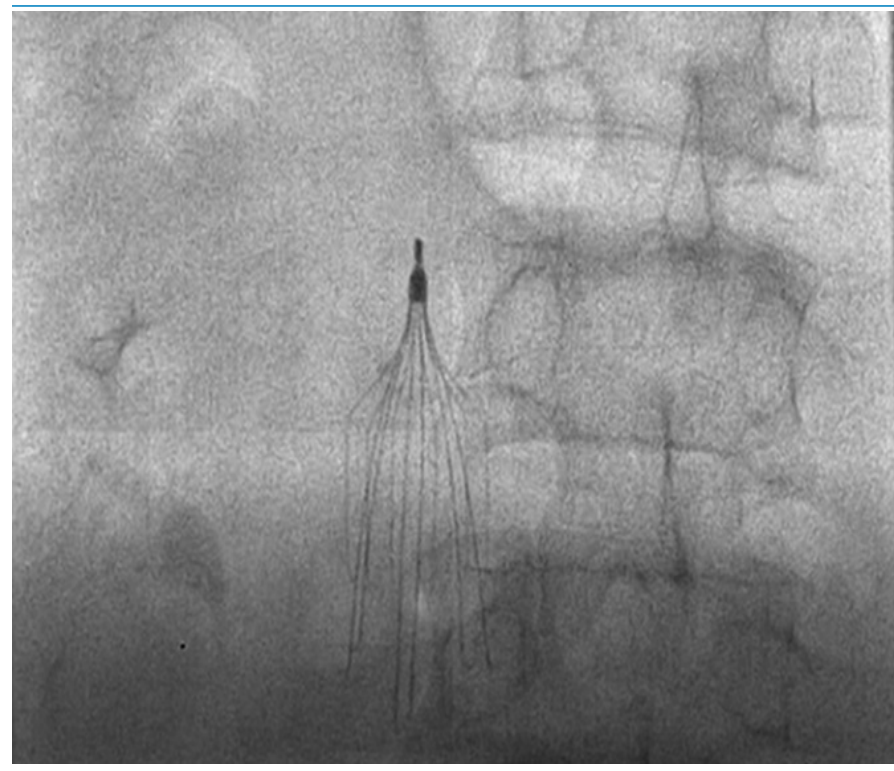

Figure 4: Infra-renal IVC filter (denali filter)

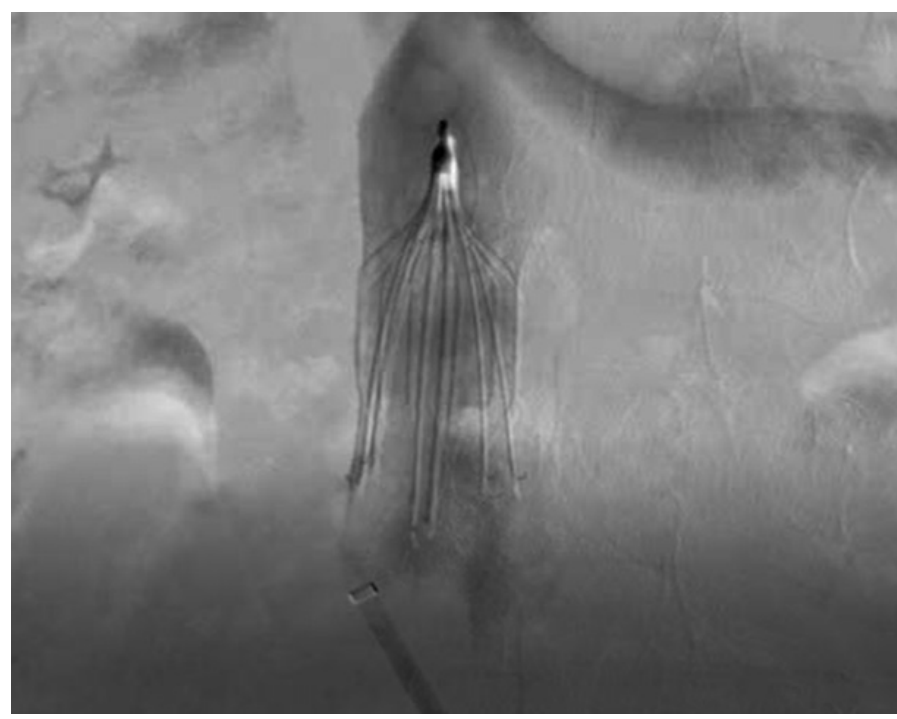

Figure 5: post-deployment venogram

Follow up: the patient improved with the recovery of most of her neurologic function. The deep venous thrombosis resolved. The Duplex ultrasound did not show DVT superficial and common femoral vein.

IVC Filter Removal: The retriever of the IVC filter was discussed with her. She was the admission at the $6^{\text {th }}$-month postDVT for IVC retriever. The Computer Tomography Venogram showed no Informed consent was taken after explaining the procedure. Access was via the right internal jugular vein with an ultrasound-assisted puncture. The 0.035 guide wires was passed with $9 \mathrm{~F}$ short sheath. The snare catheter was advanced over the guide wire and positioned closed to the filter. The snare wire was passed through the catheter to trap the hook of the filter. The snare catheter was advanced over the snare wire to collapse the filter into the catheter. Then the filter and the catheter were removed (see figure 6, a, b, c). the patient was discharged the home the same day after 4 hours post-procedure.

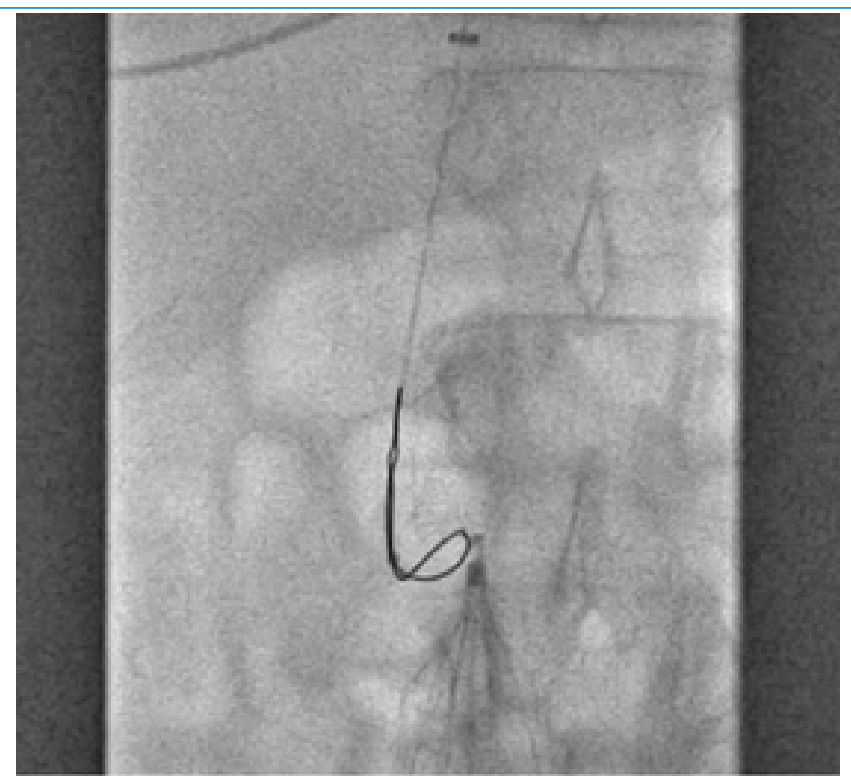

a. Snare approaching the filter

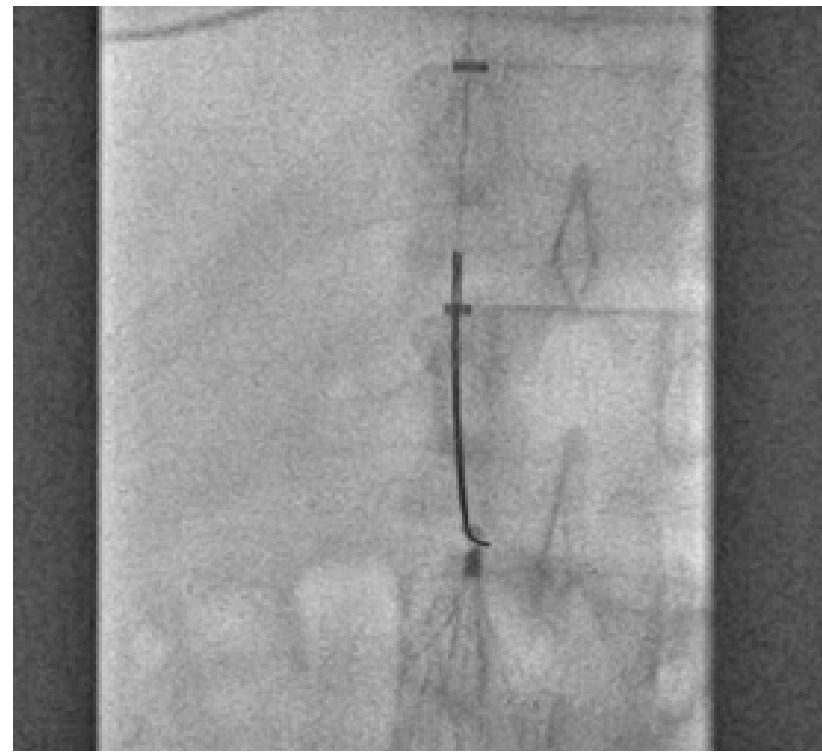

b. the snare on the hook of the filter

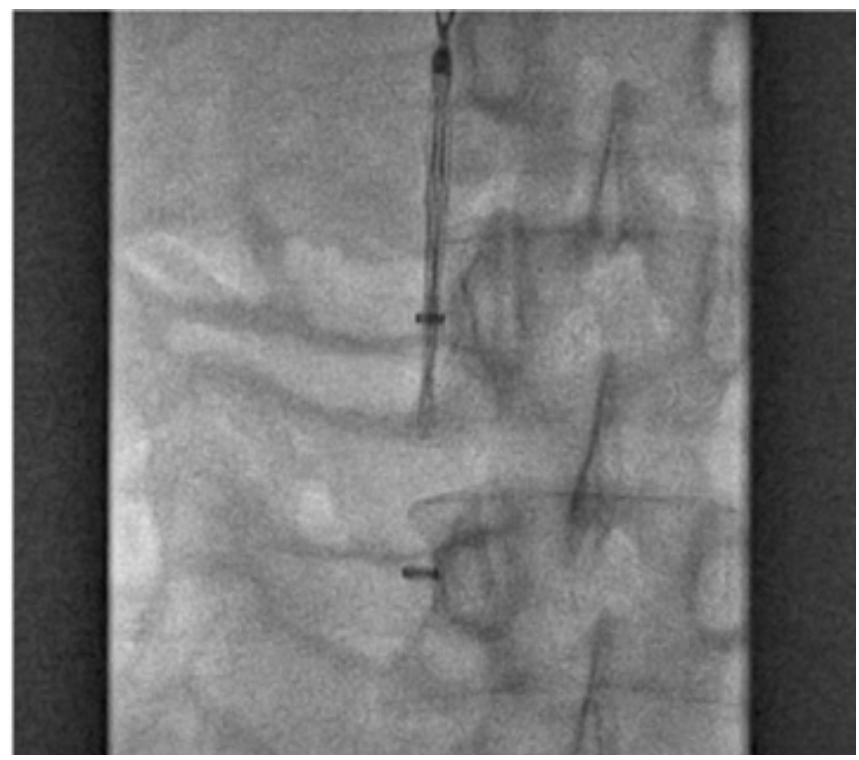

c. the filter collapsed in the snare catheter Figure 6. Retriever of the IVC filter 


\section{Discussion}

Venous thromboembolism comprised Deep Venous Thrombosis (DVT) and pulmonary embolism (PE) [4]. It is a continuum of a single disease process within the veins that drain blood to the right-sided heart and continue to the pulmonary artery [4]. The 3 case series above had DVT with the $2^{\text {nd }}$ case diagnosed with pulmonary embolism. Commonly, DVT develops within the deep veins of the lower extremities or pelvic region [3]. But, it can also arise from upper extremities or devices such as a pacemaker, implantable cardioverter defibrillators, cardiac Resynchronization therapy, and long term tunnel dialysis catheters [5]. Our 3 patients presented, had DVT of the lower extremities. The filters were placed for various reasons in these $3 \mathrm{pa}-$ tients. The first case had massive upper gastrointestinal bleeding on anticoagulation. The second case had recurrent DVT with pulmonary embolism while on anticoagulation. The third case had a hemorrhagic stroke and developed extensive DVT while on admission. Inferior vena cava filter is not part of the management plan for DVT from upper extremities and cardiac devices.

The most dreaded complication of DVT is pulmonary embolism [4]. Pulmonary embolism is the frequent cause of death among patients with venous thromboembolism [4]. One patient had pulmonary embolism among the 3 patients reported. Death is associated with serious underlying disease in approximately $50 \%$ of patients with massive pulmonary embolism [6].

The mainstay of DVT and pulmonary embolism is Systemic anticoagulation with intravenous heparin followed by oral warfarin or Non-Vitamin K antagonist oral anticoagulants (NOAC). However, as many as $33 \%$ of patients will develop a second PE while receiving adequate anticoagulation therapy [7]. The second case reported developed pulmonary embolism while on oral anticoagulation. Also, anticoagulation therapy is associated with bleeding. This limits its use in certain groups of high-risk patients, including patients at high risk for falling, hemorrhagic stroke, metastatic disease, or bleeding diathesis. The first case was on warfarin after DVT. But he developed massive upper GI bleeding that necessitated 12 units of packed cell transfusion within 24 hours. The third patient had a hemorrhagic stroke and while being managed in the hospital developed DVT.

The indications for IVC filter placement have expanded over the years. However, the main indications still remain DVT or PE in a patient for whom anticoagulation therapy is contraindicated, accounting for $38-77 \%$ of patients undergoing
IVC filter placement [8]. Our 3 cases reported had contraindications to anticoagulation, hence the need for IVC filter.

The contraindications to anticoagulation therapy are hemorrhagic stroke, recent neurosurgical procedures, major or multiple trauma, active internal bleeding (examples include upper or lower gastrointestinal bleeding, hematuria, hemobilia), Intracranial neoplasm, Bleeding diathesis (examples include secondary thrombocytopenia, idiopathic thrombocytopenic purpura, hemophilia) [9]. The first case had massive upper GI bleeding while on anticoagulation for DVT. The second case had pulmonary embolism and DVT while on anticoagulation. The third case had had a hemorrhagic stroke and DVT.

The concern about the possibility of IVC filter precipitating renal vein thrombosis has prompted many to recommend that vena cava filters be placed in the infrarenal portion of the inferior vena cava [10]. The 3 patients reported had infra-renal IVC filters. Supra-renal IVC filter placement is a valuable technique that helps to prevent pulmonary embolism in the patient that has an indication for IVC filter but contraindication to infra-renal placement.

The development of advanced retrieval techniques has improved the removal of problematic or embedded devices. Key retrieval Techniques include the following: Realignment, Stiff wire Displacement, Dual access, Sling, Sandwich and Dissection techniques. These techniques are used to remove filters once the need for filter coverage is over. Implantations and retrievals are done by the cardiologists and radiologists [11].

\section{Realignment technique}

In the realignment technique, a loop snare with single access, curved or angled angiographic or guiding catheter allow sufficient redirection of the snare toward the filter apex, prolapse it between filter \& IVC wall. The filter is grasped and realigned. The maneuver allows the filter to be removed with a snare or pulled to a more central orientation for retrieval cone. This is shown in figure 6 below. 


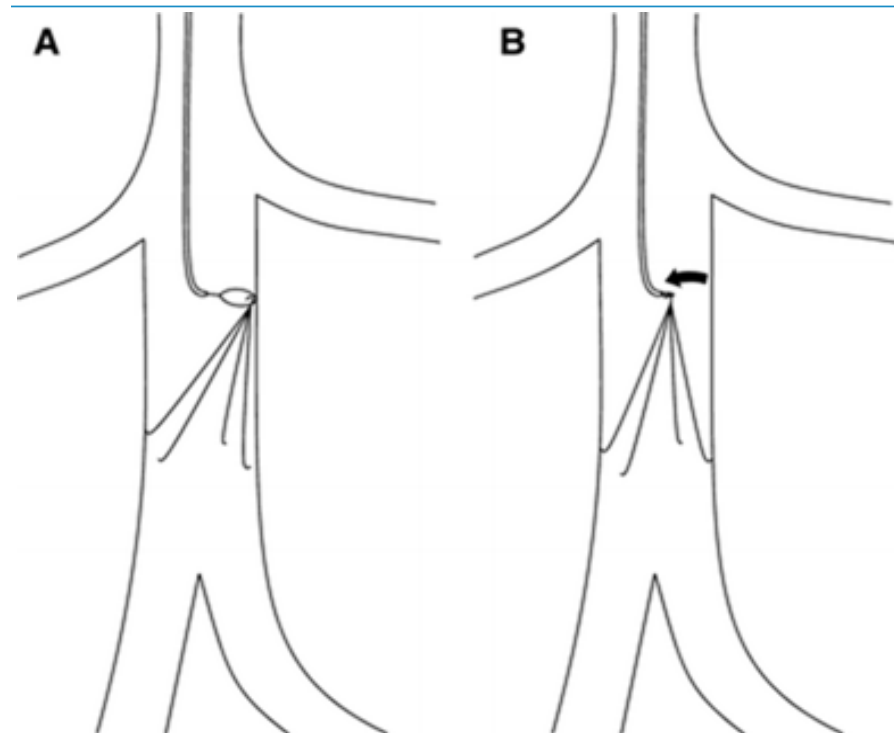

Figure 7: Realignment technique (loop snare with single access). A Curved guiding catheter is used to redirect the snare toward the filter apex. B Filter apex is grasped with the snare and realigned with the axis of the cava (curved arrow). This was the procedure done for case 3 patients.

\section{Stiff Wire-Displacement Technique}

Tilted filter's apex difficult to conventionally engage and displaced away from the caval wall with stiff straight wire between filter apex and caval wall (see figure 8). Retrieval cone advanced into IVC to grasp filter and wire. This technique can be used from a jugular approach for cone-shaped IVC filters or a femoral approach for trapezoidal filters.
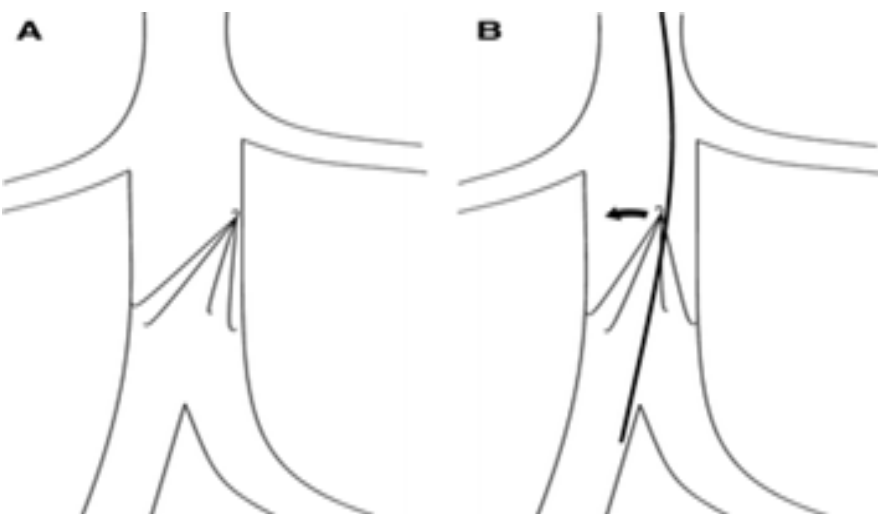

Figure 8: Stiff wire-displacement technique shown in A and B

\section{Dual-Access Technique}

It is a through-and-through "flossing" approach that increases the distraction force on the tilted non embedded or mildly epithelialized filter (see figure 9). Jugular and femoral vascular access are required. Stiff wire introduced from the femoral or jugular approach, directed btw the filter apex and IVC wall, and snared from the alternate approach. Wire traction applied in caudal and cephalic directions simultaneously. The through- and-through wire should be protected by long covering sheaths or catheters to prevent entry or pelvic vein lacerations during this maneuver (i.e. "cheese-slicing"). This approach can release the filter apex from the IVC wall. Snare introduced through the direction of retrieval would remove the repositioned filter.

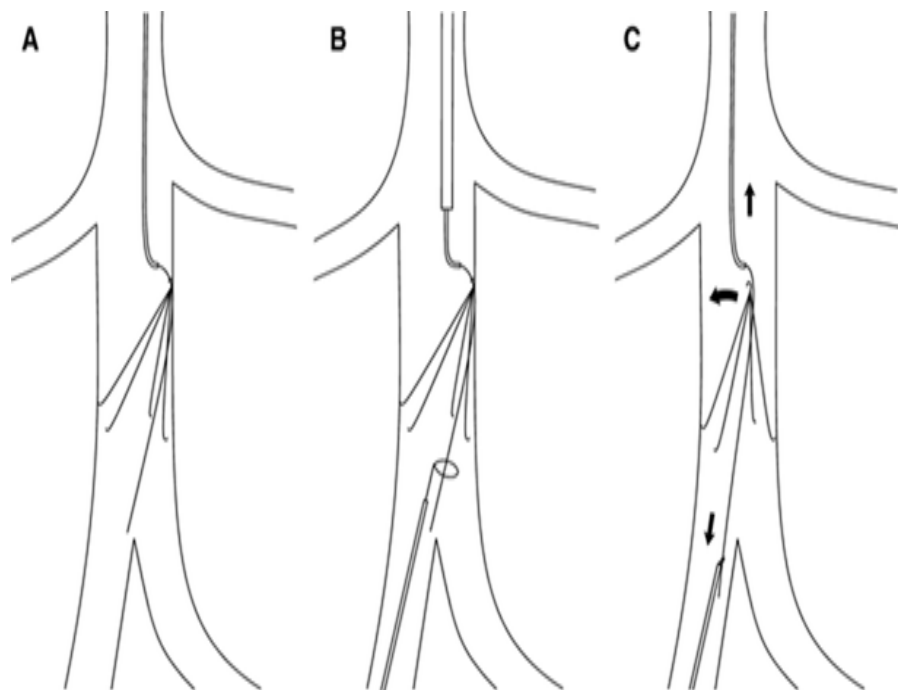

Figure 9: Dual-access technique (wire and snare with dual access). A Wire is introduced by way of jugular access and directed between filter apex and cava wall with the aid of a curved-tip guiding catheter. B The wire is snared by way of the femoral approach. C Wire traction is applied simultaneously in caudal and cephalic directions (straight arrows) resulting in the displacement of the filter apex from the cava wall (curved arrow).

\section{Balloon-Displacement Technique}

This technique involves the filter being shimmied away from IVC with an interposed angioplasty balloon (see figure 11). Balloon inflated between the apex of filter or embedded struts, removed from the caval wall. The technique very important for severely tilted filters.

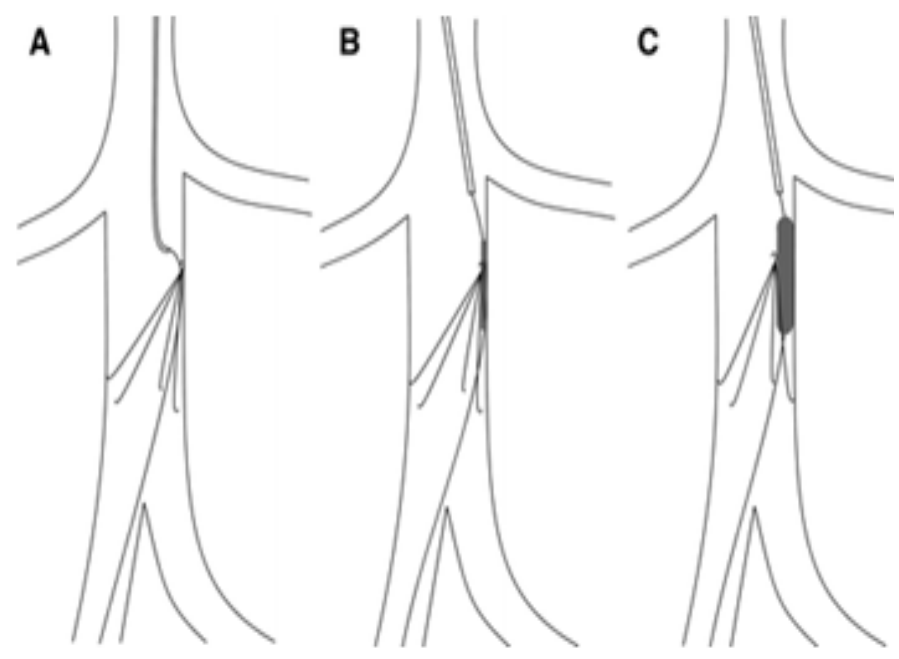

Figure 11: Balloon-Displacement Technique in A, B and C 


\section{Sling Technique}

This technique is useful in a single-access "sling" approach filter with embedded apex. Short-radius reverse-curve catheter, positioned below the retrieval zone of filter to direct guide wire backward in "U-turn" fashion. Para-axial snare, placed through the same outer sheath to grasp the guide wire and exteriorize it .Applicable in tilted IVC filters not removed by standard techniques. Nitinol wire, super elastic with kink resistance, recommended for this approach.

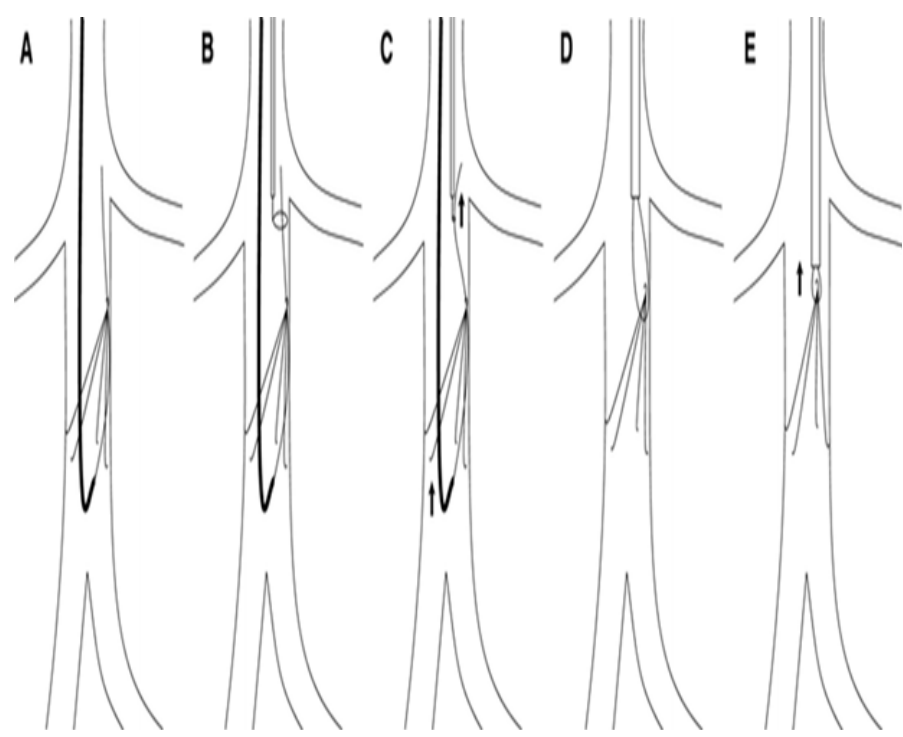

Figure 12: Sling Technique in A, B, C, D, and E

\section{Sandwich Technique}

Guide wires passed through a guiding catheter along either side of the filter's "nose," through opposing sheaths. Long catheter \& sheath advanced into snug contact against the filter, upward or downward force is selectively \& repetitively applied to "rock" the filter-free. The technique can be attempted with a single wire, but the use of parallel wires is recommended to better encapsulate the "neck" of the filter (figure 13). The approach might also minimize filter disassembly during the traction. Retrieval sheath is used to remove the disengaged filter

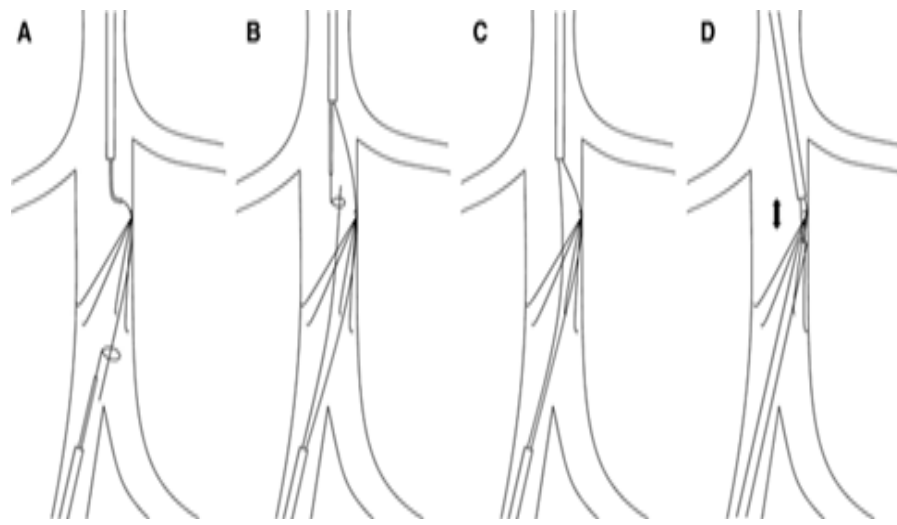

Figure 13: Parallel wire and dual-sheath technique in A, B, C and

\section{Dissection Technique}

Densely embedded filters in the IVC wall can be removed by micro dissecting the surrounding tissue with rigid bronchoscopy forceps. The technique is useful for both coneshaped and trapezoidal filters. More invasive than simpler snare and displacement techniques. Risk vessel perforation or rupture, hence the referral to experienced centers encouraged.
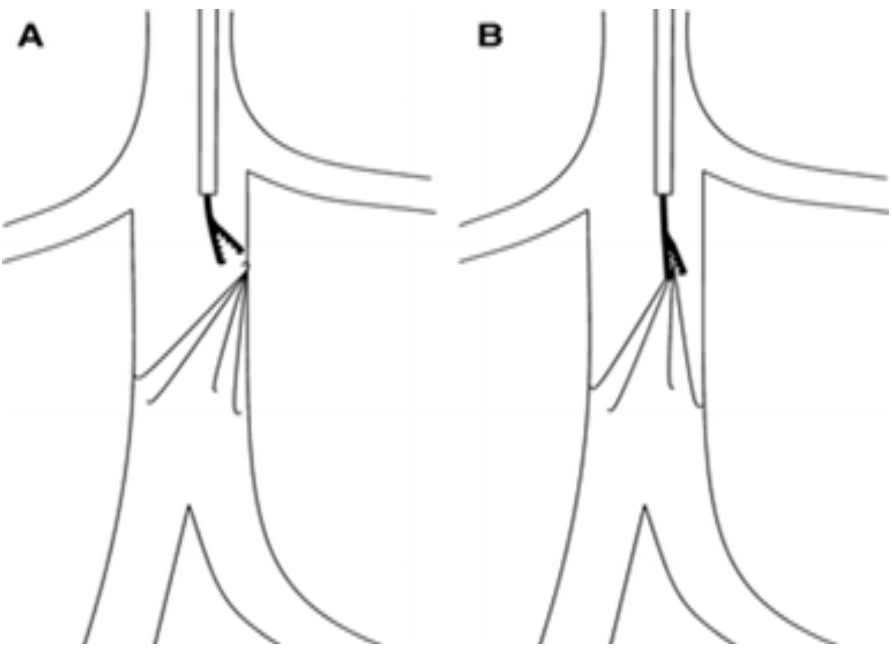

Figure 14. Dissection Technique

\section{Advantages of filter removal}

IVC retrieval helps to reduce the risk associated with having a permanent IVC filter (a foreign body within the human body). The following complications can be ameliorated by retrieval of the IVC filter.

a. Occlusion of the filter due to thrombus is the most frequent complication of the filters. $[12,13,14]$ The filter related thrombosis is more with permanent filters [13]. The thrombosis was significantly decreased with the temporary filters [14].

b. IVC filters left in-situ for a long time have been found to develop device-related complications such as fracture, device migration, organ penetration, and IVC perforation. IVC perforation is suspected when the filter components extend $3 \mathrm{~mm}$ beyond the IVC wall on CT scan [15].

\section{Indications for remover of ivc filters}

a. IVC filter is removed as soon as the underlying indication for filter deployment was over [16].

b. For the patients who cannot take anticoagulation temporarily, as the immediate postoperative period, the implanted IVC filter should be removed once the patient becomes eligible to take anticoagulation.

$\mathrm{D}$ 
c. IVC filter implanted for prophylactic reasons like immobilization, the filter should be removed once the patient is ambulated.

d. Special attention should be paid to prophylactic filters placed in trauma patients, a situation in which the filter can typically be removed within a relatively short time interval as patients begin to ambulate or are transitioned to anticoagulation [17].

\section{Conclusion}

IVC filter placement is a valuable technique that helps to prevent pulmonary embolism in a patient with DVT and have contra-indication for anticoagulation or its failure.

\section{References}

1. Goldhammer E, Mesnick N, Abinader EG, Sagiv M (1999) Dilated inferior vena cava: a common echocardiographic finding in highly trained elite athletes, J Am SocEchocardiogr 12: 988-993.

2. Lang RM, Bierig M, Devereux RB, Flachskampf FA, Foster E, Pellikka PA, et al. (2005) Recommendations for chamber quantification: a report from the American Society of Echocardiography's Guidelines and Standards Committee and the Chamber Quantification Writing Group, developed in conjunction with the European Association of Echocardiography, a branch of the European Society of Cardiology, J Am SocEchocardiogr, 18 :1440-1463.

3. van Langevelde K, Srámek A, Vincken PWJ, van Rooden JK, et al. ( 2013) Finding the origin of pulmonary emboli with a total-body magnetic resonance direct thrombus imaging technique. Haematologica 98: 309 -315.

4. Tritschler T, Kraaijpoel N, Le Gal G, Wells PS (2018) Venous Thromboembolism: Advances in Diagnosis and Treatment. JAMA 320:1583-1594.

5. Safi M, Akbarzadeh MA, Azinfar A, Namazi MH, Khaheshi I (2017) Upper extremity deep venous thrombosis and stenosis after implantation of pacemakers and defibrillators; A prospective study. Rom J Intern Med. 55:139-144.

6. Stein PD, Henry JW (1995) Prevalence of acute pulmonary embolism among patients in a general hospital and at autopsy.Chest 108: 978- 981.

7. Barnes GD, Kanthi Y, Froehlich JB (2015) Venous thromboembolism: Predicting recurrence and the need for extended anticoagulation. Vasc Med. 20: 143-152.

8. Duffett L, Carrier M. Inferior vena cava filters. Journal of Thrombosis and Haemostasis 15: 3-12.

9. Steinberg BA, Greiner MA, Hammill BG, Curtis LH, Benjamin EJ, Heckbert SR et al. (2015) Contraindications to Anticoagulation Therapy and Eligibility for Novel Anticoagulants in Older Patients With Atrial Fibrillation. Cardiovasc Ther 33: $177-183$.

10. Janvier AL, Hamdan H, Malas M (2010) Bilateral renal vein thrombosis and subsequent acute renal failure due to IVC filter migration and thrombosis. Clin Nephrol 73: 408-412. 
11. Morris E, Duszak R Jr, Sista AK, Hemingway J, Hughes DR, (2018) National Trends in Inferior Vena Cava Filter Placement and Retrieval Procedures in the Medicare Population Over Two Decades. J Am CollRadiol. 15:1080-1086.

12. Imberti D, Ageno W, Carpenedo M, et al. (2006) Retrievable vena cava filters: a review. Curr Opin Hematol. 13: 351356.

13. Simon M, Athanasoulis CA, Kim D, et al. (1989) Simon nitinol inferior vena cava filter: initial clinical experience. Work in progress. Radiology 172: 99-103.

14. Asch MR (2002) Initial experience in humans with a new retrievable inferior vena cava filter. Radiology. 225: 835-44.

15. Imberti D, Ageno W, Dentali F, et al. (2012) Retrievable vena cava filters: a clinical review. J Thromb Thrombolysis.

16. Rogers FB (2001) Venous thromboembolism in trauma patients: a review. Surgery 130: 1-12.

17. Sarosiek S, Crowther M, Sloan JM, et al. (2013) Indications, complications, and management of inferior vena cava filters: the experience in 952 patients at an academic hospital with a level I trauma center. JAMA Intern Med. 173: 513-517.
Submit your manuscript to a JScholar journal and benefit from:

๑ Convenient online submission

ब Rigorous peer review

I Immediate publication on acceptance

- Open access: articles freely available online

q High visibility within the field

- Better discount for your subsequent articles

Submit your manuscript at http://www.jscholaronline.org/submit-manuscript.php 